\title{
The Relationship between Separation and Performance Management System of Academics in Nigerian Universities: The Mediating Effect of e-HRM
}

\author{
Abubakar Allumi Nura ${ }^{1^{*}}$ and Osman Nor Hasni ${ }^{2}$ \\ ${ }^{1}$ Department of Technology and Operations Management, School of Technology \\ Management and Logistics, College of Business, University Utara Malaysia, Kedah, \\ Malaysia. \\ ${ }^{2}$ Department of Technology and Operations Management, School of Technology \\ Management and Logistics, College of Business, University Utara Malaysia, Kedah, \\ Malaysia.
}

\section{Authors' contributions}

This work was undertaken as a team by the author AAN is a PhD student and author ONH is the guide. No responsibilities shared it is a product of teamwork. All authors read and approved the final manuscript.

\section{ABSTRACT}

Aims: To reveal how the relationship between employee separation and employee performance management could be reconciled via electronic human resource management (e-HRM)

Study Design: Multimode survey technique.

Place and Duration of Study: Ahmadu Bello University Zaria, Bayero University Kano and Usmanu Danfodiyo University Sokoto from January to July, 2013.

Methodology: The paper employs a quantitative research methodology using a systematic sampling technique. Three universities were sampled in Nigeria. The data collected was subjected to series of analyses using SPSS version 19 and Smart PLS.

Results: The results obtained revealed a mediation effect of e-HRM on the relationship between employee separation and employee performance management. This was confirmed through the t-value of 2.4540088 which is statistically significant at 0.05 level. 
Conclusion: No organization would embrace employee separation but the fact that is inevitable, making adequate preparation for it becomes even more a sine qua non.

Keywords: Employee separation; employee performance management system; e-HRM; Nigeria.

\section{INTRODUCTION}

There are mainly two known different disputations about employee separation i.e. it is mainly triggered by the desire of employees for an increased paycheck and from the other angle it was only seen as a sort of movement that is very damaging to career building [1]. Irrespective of what form of argument one holds on to, the only certain thing about employee separation is that it happens no matter what, either as a sort of protest against un satisfaction (i.e. increased pay) or as a necessity (such as retirement or dismissal).

Virtually all the public universities in Nigeria battle with issues concerning employee performance management and their worst nightmare - brain drain. Experts are quitting their appointments with the universities unceremoniously as a result of inability to uphold the intellectual contract and honor agreement between the federal government and the universities. It has been relatively argued by [2] that the aftermath of such movement (the brain drain) translates that the university system and perhaps the entire education sector is and will continue to be exposed to a huge negative loss of potential. However, another alternative to curtailing brain drain and solidify the strength of realizing the central of objective of producing quality graduates could be through the adoption of e-HRM. In a similar fashion, [3] pointed out that consideration of employee attitude and behavior is paramount for effective performance management to take precedence in any goal oriented organization.

\subsection{Research Questions}

i) Is there any relationship between separation and performance management system among academics in Nigerian universities?

ii) Is there any relationship between e-HRM and performance management system among academics in Nigerian universities?

iii) Does e-HRM mediates the relationship between separation and performance management system among academics in Nigerian universities?

\subsection{Research Objectives}

i) To examine the relationship between separation and performance management system among academics in Nigerian universities

ii) To examine the relationship between e-HRM and performance management system among academics in Nigerian universities

iii) To examine the mediating effect of e-HRM on the relationship between separation and performance management system among academics in Nigerian universities 


\subsection{Research Hypotheses}

i) That separation is significantly related to performance management system among academics in Nigerian universities

ii) That e-HRM is significantly related to performance management system among academics in Nigerian universities

iii) That e-HRM mediates the relationship between separation and performance management system among academics in Nigerian universities

\section{RELATED LITERATURE}

e-HRM could be interpreted as the managerial hold up of the human resource management (HRM) functions and practices in an organization via internet technology. However, as argued by [4] e-HRM is more than just the technology factor, e-HRM is rather a comprehensive way of exercising responsibilities in the organizations in the course of a mindful and directed support of web-technology-based channels. Borrowing the argument of $[5,6]$ the awareness of e-HRM in industries should fit well with strategic organizational needs of the public institutions as well vis-à-vis personnel in general. Little is known about this fit, however, relative to this point, the potential insight about e-HRM is that it is an attempt by the strategic level within the organization to lighten up operational HRM work on employees and correspondingly, boost up quality performance.

In terms of opportunity re discovery, one popular area where e-HRM discourse is very eminent is perhaps the aspect of training and development. It is also gaining prominence in training needs assessment, e-learning related activity as well as in career management [7]. More interestingly, this paper was able to gather from literature that organizations around the globe use e-HRM for a number of activities such as e-performance management, e-360 appraisal, e-skills management, e-training administration, e-learning resources, erecruitment, e-salary review, e-employment equity, e-leave, e-discipline and e- succession planning, all these integrated into overall technology-based human capital management systems [8].

e-HRM entails putting an eye on the academics in advance by managing their talents electronically which makes it possible to identify their grievances and signs of their intent to head off from the university. That will enable the management to take remedial and timely action as well as make adequate preparations for separation process. However, regardless of the domino effect of remedial actions, it is meaningful doing the whole lot possible to counter negative emotions which also affect the quality of service and outward image of the university. In view of this therefore, it is clear that the current demand for improvements on the education system efficiency, accessibility, wellbeing and ensuring quality and contentment of both the academics and student in Nigeria could be achieved through successful implementation of e-HRM.

\section{METHODOLOGY}

This paper was designed to follow the quantitative research approach. Three federal universities were selected in North Western Nigeria (i.e Ahmadu Bello University Zaria; Bayero University Kano and Usmanu Danfodiyo University Sokoto). The reason why the North West region was used is because it is the largest in terms of population and the selected universities are the oldest in the region. 


\subsection{Research Design}

This paper employs a multimode survey strategy to obtain data this involves face to face questionnaire administration in Ahmadu Bello University Zaria and Usmanu Danfodiyo University Sokoto while an online survey was conducted for the respondents in Bayero University Kano. The reason behind this is that there were security challenges in Kano state at the time of this research. Academic members of staff were randomly selected and they comprise the unit upon which analyses were made.

\subsection{Research Population}

The target population for this study is all the academic staffs (Teaching staff) in the whole of higher educational institutions in Nigeria and the accessible population are the members of academic staff of the three selected universities (Ahmadu Bello University Zaria, Bayero University Kano and Usmanu Danfodiyo University Sokoto) in North western Nigeria, a total of 3627 members of staff as at the time of this study.

\subsection{Research Sample}

To be able to reduce sampling errors, [9] provided an easier means of achieving a good sample size using a given formula and a comprehensive table regarding a definite population figure hence the stress of calculation is relieved of researchers. The fact that 3627 was not reflected in the Krejcie and Morgan's table, the researchers used 357 which are for 5000 population size as sample size. The justification for picking a higher number is in the argument put forward by [10] who suggested that at least $50 \%$ of the sample size be added to attain accuracy.

\subsection{Instrumentation}

Single questionnaire instrument that was designed on 5-point likert scales to measure the various variables was used. All scales were adopted from various items where their validity has been established. The study also further conducted validity and reliability analysis and a composite reliability was also used to confirm the reliability of each of the items. Multicollinearity assessment and a test of mediation effect were as well undertaken.

\section{FINDINGS}

This study presents the findings in different forms, the preliminary analyses such as the correlation analysis and multicollinearity diagnostics were done in SPSS version 19 and measurement and structural model evaluations were carried out in the SmartPLS 2.0 M3 [11].

\subsection{Correlation Analysis}

To ascertain precision in the interpretation of this study, research interpretations, a table was provided which displays the results of Pearson correlation coefficients that was undertaken in order to have a clear understanding of the correlation between the study variables. As displayed in the Table 1, the values of entire correlation in all the variables are positive and statistically significant at $P<0.01$. 
The Table 2 indicates that SEP (separation) they show tolerance and VIF values of 0.390 and 2.563 and e-HRM (electronic human resource management) as shown in the table, has tolerance and VIF values 0.827 and 1.209. This implies that there is no threat of multicollinearity.

Table 1. Pearson bivariate correlation analysis

\begin{tabular}{|c|c|c|c|c|}
\hline & & EMPM & SEP & e-HRM \\
\hline \multirow{3}{*}{ EMPM } & Pearson Correlation & 1 & .448 & .307 \\
\hline & Sig.(2tailed) & & & 0 \\
\hline & $\mathrm{N}$ & 321 & 321 & 321 \\
\hline \multirow[t]{3}{*}{ SEP } & Pearson Correlation & $.448^{\pi x}$ & 1 & $.332^{x \pi}$ \\
\hline & Sig.(2tailed) & 0 & & 0 \\
\hline & $\mathrm{N}$ & 321 & 321 & 321 \\
\hline \multirow[t]{3}{*}{ e-HRM } & Pearson Correlation & $.307^{* \pi}$ & $.332^{\star x}$ & 1 \\
\hline & Sig.(2tailed) & 0 & 0 & \\
\hline & $\mathrm{N}$ & 321 & 321 & 321 \\
\hline
\end{tabular}

Table 2. Regression analysis and multicollinearity test

\begin{tabular}{|c|c|c|c|c|c|c|c|c|}
\hline & \multicolumn{2}{|c|}{ Unstand. Coeff } & \multirow{2}{*}{$\begin{array}{l}\text { Stand. Coeff } \\
\text { Beta }\end{array}$} & \multirow[t]{2}{*}{$\mathbf{t}$} & \multirow[t]{2}{*}{ Sig. } & \multicolumn{2}{|c|}{$\begin{array}{l}\text { Collinearity } \\
\text { Statistics }\end{array}$} \\
\hline & & B & $\begin{array}{l}\text { Std. } \\
\text { Error }\end{array}$ & & & & Tolerance & VIF \\
\hline 1 & $\begin{array}{l}\text { (Const) } \\
\text { SEP } \\
\text { e-HRM }\end{array}$ & $\begin{array}{l}-2.31 \mathrm{E}-06 \\
-0.038 \\
0.113\end{array}$ & $\begin{array}{l}0.042 \\
0.067 \\
0.046\end{array}$ & $\begin{array}{l}-0.038 \\
0.113\end{array}$ & $\begin{array}{l}0 \\
-0.564 \\
2.459 \\
\end{array}$ & $\begin{array}{l}1 \\
0.573 \\
0.014 \\
\end{array}$ & $\begin{array}{l}0.39 \\
0.827 \\
\end{array}$ & $\begin{array}{l}2.563 \\
1.209 \\
\end{array}$ \\
\hline
\end{tabular}

\subsection{Measurement Model}

In Smart PLS analysis, an evaluation of a measurement model becomes paramount to be able to determine the validity and reliability of the scales used as well as the ability of the model to predict outcome of relationship among constructs. This study evaluates the measurement model by conducting the convergent validity analysis, reliability analysis, discriminant validity test, assessment of the predictive relevance of the model and the determination of the goodness of fit (GoF). First, Table 3 below displays the result of convergent validity test.

The validity of a measurement scale becomes convergent if the items posses a loading greater than 0.5 on their constructs [12] and if there no any other item that loads higher than the one it measures. In Table 3 above the 12 items load appropriately on their constructs and have gone beyond the yardstick of 0.5 . More so, all the items load highly on their constructs than other constructs. In Table 4, the reliability analysis was shown.

The three variables in Table 4 show composite reliability values of 0.80 and above and corresponding AVE values greater than the threshold of 0.5 indicating a strong reliability. The values obtained for the variables are: .87113 for performance management system (EMPM), .88989 for employee separation (SEP), .86527 electronic human resource management (e-HRM). An analysis of discriminant validity was shown in Table 5. 
Table 3. Convergent validity

\begin{tabular}{llll}
\hline & EMPM & SEP & e-HRM \\
\hline EMPM1 & 0.72338 & 0.337946 & 0.321313 \\
EMPM 2 & 0.76721 & 0.361295 & 0.333518 \\
EMPM 3 & 0.77848 & 0.406759 & 0.304438 \\
EMPM 4 & 0.7359 & 0.285903 & 0.288556 \\
EMPM 5 & 0.75136 & 0.359793 & 0.362362 \\
SEP1 & 0.388487 & 0.833577 & 0.54297 \\
SEP2 & 0.461476 & 0.867664 & 0.51535 \\
SEP3 & 0.340391 & 0.821204 & 0.511766 \\
SEP4 & 0.290085 & 0.745832 & 0.477591 \\
e-HRM1 & 0.369165 & 0.511897 & 0.817159 \\
e-HRM2 & 0.343395 & 0.515452 & 0.824051 \\
e-HRM3 & 0.326552 & 0.522449 & 0.835442 \\
\hline
\end{tabular}

Table 4. Composite reliability and AVE

\begin{tabular}{lll}
\hline Construct & AVE & Composite Reliability \\
\hline EMPM & 0.57509 & 0.87113 \\
SEP & 0.66958 & 0.88989 \\
e-HRM & 0.68162 & 0.86527 \\
\hline
\end{tabular}

Table 5. Discriminant validity

\begin{tabular}{llll}
\hline & EMPM & SEP & e-HRM \\
\hline EMPM & 0.74131 & & \\
SEP & 0.457027 & 0.81828 & \\
e-HRM & 0.419814 & 0.625768 & 0.90862 \\
\hline
\end{tabular}

Discriminant validity offers a concrete explanation on whether the measures of constructs that are not supposed to be related are actually related. To be able to ascertain the discriminant validity, this study followed the argument of [13] by using the square root of the AVE for each construct. The result of these squreroot was presented along the diagonal. As pointed out by [14], for a sound discriminant validity to emerge, all the diagonal elements should possess a value greater than those elements that are off the diagonal. Table 6 displayed the result of the predictive relevance analysis.

Table 6. Predictive relevance

\begin{tabular}{llll}
\hline Total & SSO & SSE & 1-SSE/SSO $\left(\mathbf{Q}^{2}\right)$ \\
\hline EMPM & 1605 & 1388.359203 & 0.134979 \\
e-HRM & 963 & 710.947163 & 0.261737 \\
\hline
\end{tabular}

The Table 6 shows that, $Q^{2}$ shows predictive ability of 0.134979 for the EMPM and 0.261737 for e-HRM. This possibly indicates that the model has a predictive relevance. Going by what [15] pointed out that if $Q^{2}>0$, the model has predictive capability. It has been argued by [16], that it is imperative to assess the model's Predictive ability in SmartPLS, this is depicted by $Q^{2}$. The $Q^{2}$ does not only assess how values are assembled around the 
model but also assesses the factor estimates. This study reports the $\mathrm{Q}^{2}$ through cross validated redundancy extracted through blindfolding. The cross validated redundancy explains the capability of the model to predict the behavior and the relationship among variables thus; it demonstrates the quality of the model. The table that followed displays the cross validated redundancy. In Table 7 that followed, the goodness of fit of the model was ascertained.

Table 7. Goodness of fit

\begin{tabular}{llll}
\hline Constructs & communality & Composite Reliability & R Square \\
\hline EMPM & 0.575093 & 0.871125 & 0.246229 \\
SEP & 0.669575 & 0.889885 & \\
e-HRM & 0.681618 & 0.865265 & 0.391651 \\
GEOMEAN & 0.640264546 & & 0.310541 \\
& & GoF & 0.198829 \\
& & & 0.445902 \\
\hline
\end{tabular}

The GoF is calculated using the following formula:

$$
\begin{gathered}
\text { GoF }=\sqrt{R^{2} \times \text { Average of Communality }} \\
\text { GoF }=\sqrt{0.640264546 \times 0.310541} \\
\text { GoF }=\sqrt{0.198829} \\
\text { GoF }=0.445902
\end{gathered}
$$

Goodness of fit (GoF) is interpreted as the product of the geometric means of two different sets of values of $R^{2}$ i.e. geometric mean of the average communality and the geometric mean of endogenous latent variables. It is shown in Table 7 that the value of GoF obtained in this study is quite impressive because GoF values $0.1=$ small; $0.25=$ medium and 0.36 $=$ large [15]. Having evaluated the measurement model, the following segment evaluates the structural model.

\subsection{Structural Model}

Structural model evaluation as thoroughly discussed by [14] is to test the hypothesized relationships among constructs. The Table 7 indicates that all the three hypothesized relationships are supported. The hypotheses are accepted based on the statistical significance at 0.05 . Table 8 displayed the results of hypotheses testing.

Table 8. Result of hypothesis testing

\begin{tabular}{llll}
\hline Relationship & Beta & T-value & Decision \\
\hline SEP -> e-HRM & 0.626 & 15.456 & Supported \\
SEP -> EMPM & 0.327 & 4.213 & Supported \\
e-HRM -> EMPM & 0.221 & 2.542 & Supported \\
\hline
\end{tabular}




\subsection{Mediation Analysis}

Mediation analysis in this study was undertaken using bootstrapping technique as thoroughly discussed by [17]. This technique was chosen because it uses standard errors for path coefficients. Using 5000 re sampling iterations as suggested by [15] the mediation test was undertaken and Table 9 displays the result of the mediation test.

\section{Table 9. Mediating effect of e-HRM}

\begin{tabular}{ll}
\hline & Mediating Effect of e-HRM \\
\hline$a^{*} b$ & 0.132195 \\
$S$ & 0.053869 \\
$T$ & 2.4540088 \\
\hline
\end{tabular}

The Table 9 above presents the result of the mediation test of e-HRM it shows a t-value of 2.45 for this interprets a significant mediation effect of e-HRM on the relationship between employee separation and performance management. It is statistically significant at $5 \%$ (0.05).

Fig. 1 displays the mediating effect model

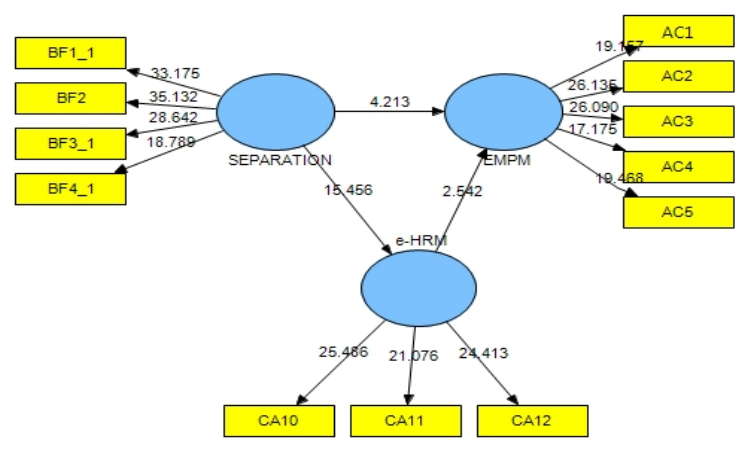

Fig. 1. The mediating effect of e-HRM

\section{DISCUSSIONS}

The first objective of this research was to examine the relationship between separation and PMS of academics in Nigerian Universities. This objective was accomplished as evidenced in the research findings obtained. The results concur with findings of scholars. For instance, [18] found out that employee separation ushers effective PMS. Similarly, [19] recognized that employee separation is paramount to PMS. Correspondingly, it has been argued that employee separation and performance management are in many instances complimentary to one another $[20,21,22]$. But nonetheless, this result to some extent in contradicts the findings of [23], who found that relationship between employee separation and PMS are as much conflicting as they are complimentary.

The second objective that aimed to determine the intervening power of e-HRM on the relationship between employee separation and performance management system was also attained. This was indicated in the analysis where the T-value indicates a significant 
relationship at $5 \%$ level of significance with a corresponding low p-value. This finding has backing from a number of empirical studies such as that of [24] who found that e-HRM has a significant intervening power. Series of other reports such as Joseph and $[25,26]$ have also made clear that e-HRM mediates the relationship between organizational success, turn over, value creation and overall performance management of employees.

\section{IMPLICATIONS}

Organizational stewardship and continuity cannot be definite without a good correlation between employee performance management and employee separation which could be reconciled through electronic human resource management (e-HRM). e-HRM has proven to be a strong antidote to organizational failures in the private sector and series of literatures point out that same could be said of e-HRM if carefully integrated in the public sector affairs.

\section{DIRECTION FOR FUTURE STUDIES}

Future studies may consider other regions in Nigeria or even attempt a comparative study across public universities or compare with the privately owned universities in Nigeria to be able to fully comprehend the connection between separation and employee performance management system.

\section{CONCLUSION}

As revealed in this study, one of the greatest problems facing Nigerian Universities is perhaps their inability to retain their staff and, e-HRM has proven to have mediated employee separation and performance management. This implies that there is need for adequate funding of the universities to be able to secure the needed environment for e-HRM to thrive.

\section{COMPETING INTERESTS}

Authors have declared that no competing interests exist.

\section{REFERENCES}

1. Fallick B, Haltiwanger J, McEntarfer E. Non employment Duration and the consequences of job separations. In Press; 2011.

2. Nura AA, Osman NH. Gauging the effect of performance management and technology based human resource management on employee retention: The perspective of academics in higher educational institutions in Sokoto State Nigeria. Asia Social Science. 2013;9(15):955-964.

3. Katou A. Investigating reverse causality between human resource management policies and organizational performance in small firms. Management Research Review. 2012;35(2):134-156.

4. Ruel HJM, Bondarouk TV, Van Der Velde M. The contribution of eHRM to HRM effectiveness: Results from a quantitative study in a Dutch Ministry. Employee Relations. 2007;29(3):280-291.

5. Gardner SD, Lepak D, Bartol KM. Virtual HR: The impact of information technology on the Human Resource professional. Journal of Vocational Behavior. 2003;63:159-179. 
6. Fletcher PAK. 2005 from personnel administration to business-driven human capital management: the transformation of the role of HR in the digital age. In greutal and stone, editors. the brave new world of eHR. San Francisco, CA: Jossey-Bass. Florkowski and Olivas-Luja'n; 2006.

7. Panayotopoulou L, Vakola M, Galanaki E. E-HR adoption and the role of HRM: evidence from Greece. Personnel Review. 2007;36(2):277-294.

8. Schramm J. 2008 HR technology competencies: new roles for HR professionals. HR Magazine. Find.Articles.Com. Assessed 8 June 2011.

Available at: http://findarticles.com/p/articles/mi m3495/ is 4 51/ai n26840916/

9. Krejcie RV, Morgan DW. Determining sample size for research activities. Educational and Psychological Measurement. 1970;30(3):607-610.

10. Bartlett JE, Kotrlik JW, Higgins CC. Organizational research: determining appropriate sample size in survey research. Information Technology. 2001;19(1):43-50.

11. Ringle C, Wende S, Will A. 2005 SmartPLS 2.0 M3. Hamburg: University of Hamburg. Assessed 6 June 2013. Available at: http://www.smartpls.de

12. Hair J, Anderson R, Tatham R, Black W. Multivariate data analysis. Upper Saddle River, NJ: Prentice-Hall International; 2010.

13. Fornell C, David FL. Evaluating structural equation models with unobservable variables and measurement error. Journal of Marketing Research.1981:8:39-50.

14. Hair J, Black B, Babin B, Anderson R, Tatham R. Multivariate data Analysis $\left(6^{\text {th }}\right.$ Edition). Upper Saddle River, NJ: Prentice Hall; 2006.

15. Hair JF, Hult MTG, Ringle MC, Sarstedt M. A primer on partial least squares structural equation modeling. London, Sage Publications; 2013.

16. Hair JF, Christian MR, Marko S. PLS-SEM: Indeed a silver bullet. Journal of Marketing Theory and Practice. 2011;19(2):139-151.

17. Hayes AF, Preacher KJ. Quantifying and testing indirect effects in simple mediation models when the constituent paths are nonlinear. Multivariate Behavioral Research. 2010;45(4):627-660.

18. Abor J, Biekpe N. Corporate governance, ownership structure and performance of SMEs in Ghana: implications for financing opportunities. Corporate Governance. 2007;7(3):288-300.

19. Beever DR. Integrating succession and career development strategy for finance professionals. Canada: Royal Roads University; 2008.

20. Abdullah Z, Abu Samah SA, Jussof K, Isa PM. Succession planning in malaysian Institution of higher education. International Education Studies. 2009;2:1

21. Gaffney S. Career development as a retention and succession planning tool. The Journal for Quality and Participation. 2005;28(3):7-10.

22. Rothwell WJ. Effective succession planning: ensuring leadership continuity and building talent from within. New York: American Management Association; 2005.

23. Ip B, Jacobs G. Business succession planning: A review of the evidence. Journal of Small Business and Enterprise Development. 2006;13(3):326-350.

24. Reiss M. 2003 Mass personalization: An internet-enabled strategy for e-HRM. Assessed 19 January 2013. Available at from: http://lfo.uni-stuttgart.de

25. Joseph R, Kitlan D. An examination of factors affecting multi level e-voting. Annual meeting of the Northeast Decision Science Institute (NEDSI), Brooklyn, NY; 2008. 
26. Loijen Y. 2011 e-HRM: From implementation to value creation: Determining the value creating factors of e-HRM. Assessed 19 March 2013.

Available at: http://www.utwente.nl/mb/ba/staff/bandarouk/..../eHRM value Loijen.pdf

(c) 2014 Nura and Hasni; This is an Open Access article distributed under the terms of the Creative Commons Attribution License (http://creativecommons.org/licenses/by/3.0), which permits unrestricted use, distribution, and reproduction in any medium, provided the original work is properly cited.

Peer-review history:

The peer review history for this paper can be accessed here:

http://www.sciencedomain.org/review-history.php?iid=441\&id=22\&aid=3799 